RES CHEM INTERMEDIATES 41: 9181-9193 (2015).

DOI: $10.1007 / \mathrm{s} 11164-015-1945-1$

\title{
Acetic acid hydroconversion to ethanol over supported nickel and indium modified nickel catalysts
}

\author{
György Onyestyák ${ }^{\mathrm{a} *}$, Szabolcs Harnos ${ }^{\mathrm{a}}$, Szilvia Klébert ${ }^{\mathrm{a}}$, Magdalena Štolcováb, Alexander Kaszonyi ${ }^{\mathrm{b}}$ and $^{\mathrm{b}}$ \\ Dénes Kalló \\ ${ }^{a}$ Institute of Materials and Environmental Chemistry, Research Centre for Natural Sciences, Hungarian \\ Academy of Sciences, Magyar Tudósok körútja 2, Budapest, Hungary, H-1117 \\ ${ }^{b}$ Department of Organic Technology, Slovak University of Technology, Bratislava, SK-81237, Slovak Republic
}

*Corresponding author. E-mail: onyestyak.gyorgy@ttk.mta.hu

\begin{abstract}
Volatile carboxylic acids (mainly acetic acid) can be produced efficiently by simple thermochemical or biological degradation of various biomasses. For the processing of such oxygenates in hydrogen atmosphere, acetic acid (AA) hydroconversion was studied in details over zeolite based $\mathrm{Ni}$ and bimetallic InNi catalysts in a flow-through reactor at 21 bar total pressure and $240-380{ }^{\circ} \mathrm{C}$. Efficient hydrogenating contacts were already obtained by in situ reduction of Ni-zeolites (A, X, P) and mainly coreduction of their mixtures with $\mathrm{In}_{2} \mathrm{O}_{3}$ in $\mathrm{H}_{2}$ flow at 21 bar and $450{ }^{\circ} \mathrm{C}$. Under these conditions the bulk of charge-compensating nickel cations remained unreduced therefore large portion of the microporous zeolite structure was still preserved. Modification of the formed Ni-particles with indium quest metal generated bimetallic NiIn/Ni,H-zeolite catalysts having higher hydroconversion activity with much lowered hydrodecarbonylation and with enhanced ethanol selectivity than the parent partially destructed Ni/Ni,H-zeolite. The activity dependence on the reactant partial pressure denotes rate-controlling surface reaction according to Langmuir-Hinshelwood mechanism.
\end{abstract}

Keywords bimetallic catalysts, $\mathrm{NiIn} / \mathrm{Ni}, \mathrm{H}-$ zeolites, $\mathrm{Cu}$-forms, acetic acid reduction 


\section{Introduction}

Recently the research efforts of biomass conversion to chemicals and fuels have significantly increased, as the necessity for the utilization of renewable carbon sources has become more evident [1-6]. The key trend today is to move away from food crops to nonfood ones. The renewable carbon sources are the carbon dioxide and the organic wastes, predominantly lignocellulosic materials. The primary degradative processing of biomasses are hydrolysis, gasification, pyrolysis and fermentation. The pyro-oils or other aqueous solutions obtained contain oxygen-rich organic compounds, referred to as platform molecules. Abundant platform intermediates are the carboxylic acids having 2 to 6 carbon atoms, including aliphatic mono- and dicarboxylic acids, the oxo or hydroxy substituted derivatives [7]. Instead of the very simple, but seriously disadvantageous thermochemical routes (as pyrolysis), a novel way, a favorable biochemical destruction (branching from the biogas process, stopped after the rapid anaerobic acidogenic digestion stage) is suggested utilising volatile fatty acids (VFAs) for production of biofuels and biochemicals [8-10]. It should be remarked that species of anaerobic bacteria, including members of the genus Clostridium, can convert directly sugar building units to AA from less expensive feeds. The overall chemical reaction conducted by these bacteria may be represented as:

$$
\mathrm{C}_{6} \mathrm{H}_{12} \mathrm{O}_{6} \rightarrow 3 \mathrm{CH}_{3} \mathrm{COOH}
$$

The carbon atom of carboxylic group is in a relatively high oxidation state. Removal of oxygen atoms by catalytic hydrogenation is extensively applied in industry. The platform molecules have to be processed in a catalytic process to obtain more valuable, less oxygen rich chemicals or fuel. Complex bi- or trimetallic heterogeneous catalysts seem to gain more and more significance in biomass upgrading technologies [7, 11-12]. Catalytic hydrodeoxygenation (HDO) is a plausible way for upgrading oxygen-rich raw materials. The value of the HDO product strongly depends on the catalytic selectivity. For instance, HDO of short chain carboxylic acids can give either gaseous hydrocarbons or liquid phase alcohols, where latter is representing higher value as chemical or fuel component.

Recent studies concern the HDO of carboxylic acids over catalysts obtained by the reduction and Inmodification of Cu-zeolites [13-15]. However, the crystalline structure of Al-rich Cu-zeolites (A, X and P) completely collapsed upon $\mathrm{H}_{2}$ reduction at temperature as low as $250{ }^{\circ} \mathrm{C}$ forming a special amorphous support of low specific surface area for active metal particles. Nevertheless, the In-additive was found to suppress successfully the total hydrogenation and decarboxylation, both resulting in hydrocarbons, and to promote alcohol formation. 
In contrast to $\mathrm{Cu}$-forms $\mathrm{Ni}$-zeolites cannot be fully reduced in $\mathrm{H}_{2}$ even above the highest $\mathrm{HDO}$ temperature applied in a previous study $\left(380^{\circ} \mathrm{C}\right)$ [16]. The residual nickel cations stabilize a relatively large part of the zeolite structure. The HDO properties of In-modified Ni-zeolite catalysts ( $\mathrm{NiIn} / \mathrm{Ni}, \mathrm{H}$-zeolite) were already scanned using octanoic acid as model compound of fatty acids [16]. Because practical reason, now the more promising acetic acid (AA) hydroconversion to ethanol was studied in more details.

\section{Materials and Methods}

Nickel-zeolite (A, X, P) catalyst precursors were prepared from NaP (Crosfield Zeocross), NaA (Baylith), $\mathrm{NaX}$ (product of the late VEB CKB, Bitterfeld-Wolfen, Germany) and NaY (Grace Corp.) powders, by conventional aqueous ion-exchange using nickel(II)acetate (Aldrich) solution. The preparations were designated as $8 \mathrm{NiP}, 13 \mathrm{NiA}, 11 \mathrm{NiA}, 10 \mathrm{NiX}$ and $6 \mathrm{NiY}$ where the number gives the $\mathrm{Ni}$ content of the sample in weight percent. For comparison of differences observed in the structural stability, $\mathrm{Cu}$-zeolites, which already were investigated in former studies [13-15], 17CuP, $15 \mathrm{CuA}$ and $15 \mathrm{CuX}$ were similarly prepared using copper(II)acetate (Aldrich) solution. Bimetallic Ni catalyst precursors were obtained by adding $10 \mathrm{wt} \%$ indium(III)oxide to the Ni-zeolite and grinding the mixture in agate mortar. The mixtures were reduced with $\mathrm{H}_{2}$ and designated as In13NiA, In11NiA, etc.

For comparison, a commercial Adkins catalyst (consisting of $72 \mathrm{wt} \% \mathrm{CuCr}_{2} \mathrm{O}_{4}$ and $28 \mathrm{wt} \% \mathrm{CuO}$ ) was also tested applying the same activation and reaction conditions as for the catalysts of the present study.

The reduction of the samples was studied using temperature-programmed $\mathrm{H}_{2}$-reduction $\left(\mathrm{H}_{2}\right.$-TPR) using a flow-through quartz microreactor. Around $30 \mathrm{mg}$ catalyst was pretreated in a flow of $30 \mathrm{ml} \mathrm{min}^{-1}$ nitrogen at $350{ }^{\circ} \mathrm{C}$ for $1 \mathrm{~h}$. The pretreated sample was then cooled to room temperature in the same $\mathrm{N}_{2}$ flow thereafter contacted with a $30 \mathrm{~cm}^{3} \min ^{-1}$ flow of $9.7 \% \mathrm{H}_{2} / \mathrm{N}_{2}$ mixture. The reactor temperature was ramped up at a rate of $10{ }^{\circ} \mathrm{C} \min ^{-1}$ to $800{ }^{\circ} \mathrm{C}$ and maintained for $1 \mathrm{~h}$ at this temperature. The effluent gas was passed through a liquid nitrogen trap and a thermal conductivity detector (TCD). Data were recorded and processed by computer. Calculation of the corresponding hydrogen consumptions based on the peak areas was carried out by using the calibration value determined with the $\mathrm{H}_{2}$-TPR of $\mathrm{CuO}$ reference materials.

The XRD patterns of the catalysts were recorded by Philips PW 1810 diffractometer at elevated temperatures in hydrogen flow using a high temperature XRD cell (HT-XRD). The crystalline phases were identified using the ICDD database. 
Nitrogen adsorption measurements were carried out at $-196^{\circ} \mathrm{C}$ using Quantochrome Autosorb 1C instrument.

Catalytic hydrogenation of AA was carried out in a high-pressure fixed bed flow-through reactor at 21 bar total pressure in temperature and space time (or WHSV) ranges of $240-380{ }^{\circ} \mathrm{C}$ and $0.3-3 \mathrm{~h}\left(\right.$ or $0.33-3.3 \mathrm{~h}^{-1}$ ),

respectively. Each catalyst precursor was reduced in hydrogen flow in situ in the reactor at $450{ }^{\circ} \mathrm{C}$ for $1 \mathrm{~h}$ in order to generate active supported metal prior to the catalytic test. The reactor effluent was cooled to room temperature and the liquid and gas phase products were separated. The liquid was analyzed using a gas chromatograph (GC, Shimadzu 2010) equipped with flame ionization detector and a Restek Rt-U-Bond capillary column. The gas was analyzed by an on-line GC (HP 5890) equipped with thermal conductivity detector and Carboxen 1006 PLOT capillary column. The activity and the selectivity of the catalysts were characterized by product distributions represented by stacked area graphs. In this representation, the distance between two neighboring curves gives the yield of the specified product in mol percent.

\section{Results and Discussion}

Formation of active hydrogenating metallic phases in the studied zeolite structures can be followed in Fig. 1 using $\mathrm{H}_{2}$-TPR technique and HT-XRD method (Figs. 2-4). Zeolite A, X and P investigated in this work have about the same low $\mathrm{Si}$ to $\mathrm{Al}$ ratio (near to 1) and, therefore, of similar chemical composition. Both zeolites, A and $\mathrm{X}$ are built up of sodalite units interconnected by hexagonal prisms, forming small $(0.41 \mathrm{x} 0.41 \mathrm{~nm})$ and large pore $(0.74 \times 0.74 \mathrm{~nm})$ structures, respectively. Zeolite $\mathrm{P}$ falls in a different zeolite class and is characterized with a gismondite framework structure (GIS) having pores as narrow as $0.45 \times 0.31 \mathrm{~nm}$. These important structural differences highly influence the reduction process of charge compensating $\mathrm{Cu}$ - or $\mathrm{Ni}$-cations located on discrete cationic sites in different microporous zeolite frameworks as demonstrated by the $\mathrm{H}_{2}$-TPR curves in Fig. 1 . It is clearly shown that transition metal cation of $\mathrm{Cu}$-zeolites are much more reducible than of the $\mathrm{Ni}$-forms in accord with the different standard reduction potentials, $+0.34 \mathrm{~V}$ and $-0.23 \mathrm{~V}$, respectively. However, beyond this basic property delicate features can be observed depending on the zeolite structure. The zeolite framework determines the locations and the accesibility of cations, consequently the mass transport resistances in micropore system for the reducing agent (hydrogen) and the products (water molecules and metal atoms). The complexity is highly enhanced by the structural instability of low-silica $\mathrm{H}$-zeolites forming in line with the reduction of $\mathrm{Cu}^{2+} \mathrm{or} \mathrm{Ni}^{2+}$ cations by hydrogen. This is especially tipical of the formerly studied $\mathrm{Cu}$-zeolites where the full reduction can be already attained at lower temperature and consequently in presence of higher zeolitic water content resulting in 
total collapse or deep damage of the crystalline microporous structure. Contrary, nickel zeolites can be reduced at much higher temperature showing less cloudy, more characteristic pictures. Containing essentionally less water and thus the zeolite crystallinity is preserved in higher degree under conditions of reduction (see later).

NiP shows only a single low temperature reduction peak around the routine pretreatment temperature $\left(450^{\circ} \mathrm{C}\right)$ in accordance with the lowest stability of this narrow pore gismondite stucture (see later). The nearly total collapse of such a structure enables at low temperature complete reduction of $\mathrm{Ni}^{2+}$ cations becoming accesible by getting free from the narrow micropores. Zeolite frameworks are really gigantic anions (crystallites of micron size) having strong electric field inside the micropores resulting in strong interactions for cations situated well definied sites. In the solid electrolite zeolite the mobility of cations is rather restricted. Additionally the diffusional resistance of mass transport for gas molecules inside the microporous crystals can be also extremely high determined by the type of the structure. Consequently for the more stable zeolite $\mathrm{A}$ and $\mathrm{X}$ reduction peaks can be detected in a wider temperature range than for easily fragmented zeolite $\mathrm{P}$ (as shown in Fig. 1). The different shape of TPR curves obtained for the narrow pore NiA and the large pore NiX can be attributed to the originally different mass transport properties, which change, however, during the reduction process followed by the damage of the structure.

Contrary to $\mathrm{H}_{2}$-TPR technique, which is a dynamical method using a linear temperature program, HT-XRD patterns were recorded applying a step-by-step heating up program while the samples are treated in $\mathrm{H}_{2}$ flow for $30 \mathrm{~min}$ at each temperatures ensuring sufficient time to attain the characteristic reduction level at the given temperature. To demonstrate the formation of mono- or bimetallic catalysts, Fig. 2, as representative example, shows the transformation of the crystalline NiA phase and the $\mathrm{In}_{2} \mathrm{O}_{3} / \mathrm{NiA}$ mixture upon treatment in $\mathrm{H}_{2}$ flow from room temperature up to $550{ }^{\circ} \mathrm{C}$. The reduction of the NiA generates $\mathrm{Ni}$ metal particles above $350{ }^{\circ} \mathrm{C}$ up to $550{ }^{\circ} \mathrm{C}$ (Fig. 2A) in accordance with the more sensitive $\mathrm{H}_{2}$-TPR measurements (Fig. 1). $\mathrm{Ni}_{2}$ In intermetallic compound, which was assigned as the novel efficient active phase of the highly selective alumina supported catalysts [17], can be detected only at $550{ }^{\circ} \mathrm{C}$ in the preparation containing both $\mathrm{In}_{2} \mathrm{O}_{3}$ and NiA (Fig. 2B). Diffraction lines of $\operatorname{In}_{2} \mathrm{O}_{3}$ already completely disappear up to $450{ }^{\circ} \mathrm{C}$, while the charge compensating $\mathrm{Ni}^{2+}$ cations can be reduced completely only at higher temperature. All the admixed $\operatorname{In}_{2} \mathrm{O}_{3}$ is converted to liquid $\operatorname{In}^{0}$ (melting point is $156.6{ }^{\circ} \mathrm{C}$ ) and new $\mathrm{Cu}_{2} \mathrm{In}$ or $\mathrm{Ni}_{2} \mathrm{In}$ bimetallic phase is formed over amorphous, mesoporous supports as observed in our former studies $[13,17]$. However, Fig. 2B demonstrates that the crystallinity of the microporous precursor, NiA zeolite is partly preserved, which can host a great part of nascent indium atoms well dispersed in the micropores. Consequently, only the residual indium atoms can form a layer of $\mathrm{Ni}_{2} \mathrm{In}$ on the outer 
surface of nickel particles. This seems to be enough thick to give diffraction line and to have the characteristic bimetallic behavior in the carboxylic acid reduction reaction (see later).

Fig. 3 summarizes and demonstrates the observable striking differences in the HT-XRD diffractograms measured over $\mathrm{Cu}$ (Fig. 3A1 and B1) or Ni (Fig. 3A2 and B2) forms of zeolite X (Fig. 3A1 and A2) and P (Fig. 3B1 and B2) with or without indium(III)oxide admission. Upon reduction, reflections of the CuP (gismondite, GIS) structure disappear up to $350{ }^{\circ} \mathrm{C}$ indicating complete collapse of the structure (Fig. $3 \mathrm{~B} 1 \mathrm{c}$ ). Copper particles are produced already at $200{ }^{\circ} \mathrm{C}$, which does not change at elevated temperature. The $\mathrm{Cu}$ form of faujasite structure seems to be a little more stable than gismondite, although copper is also fully reduced up to $350{ }^{\circ} \mathrm{C}$ (Fig. $\left.3 \mathrm{~A} 1 \mathrm{c}\right)$.

In NiP reflections only became weaker and the GIS framework slightly expanded at the elevated temperature of the reduction as indicated by the somewhat higher $2 \Theta$ degrees of the residual reflections (Fig. 3 B2 e, f). The intensity decrease of the diffraction lines from the GIS structure can indicate partial destruction of the zeolite structure upon reduction of the $\mathrm{Ni}^{2+}$ lattice cations. However, the changed scattering properties of the material because of the formation of nickel nanoparticles is a possible other reason of intensity change of zeolite reflections. $\mathrm{Ni}^{2+}$ cations can be reduced fully only at $550{ }^{\circ} \mathrm{C}$. The reductive reaction of $\mathrm{NiX}$ is only slightly different from that of NiP (Fig. 3 A2 e, f). A large fraction of nickel cations in NiX cannot be reduced up to $450{ }^{\circ} \mathrm{C}$. Consequently $\mathrm{NiX}$ hardly suffered structural destruction during reduction up to about $450{ }^{\circ} \mathrm{C}$, the routine pretreatment temperature.

All the admixed $\operatorname{In}_{2} \mathrm{O}_{3}$ can be converted up to $450{ }^{\circ} \mathrm{C}$ to $\mathrm{In}^{0}$ and that can form immediately a new $\mathrm{Cu}_{2} \mathrm{In}$ bimetallic phase (see in Fig. 3 A1 c', e' and B1 c', e') using CuP or CuX. The intensity of the $\mathrm{Ni}_{2} \mathrm{In}$ diffraction lines are in line with the degree of nickel reduction that is higher after higher $\mathrm{H}_{2}$ treatment temperature investigated the $\mathrm{In}_{2} \mathrm{O}_{3} / \mathrm{NiP}$ mixture (Fig. $3 \mathrm{~B} 2 \mathrm{e}^{\prime}, \mathrm{f}^{\prime}$ ). The reductive conversion of the $\mathrm{NiX} / \mathrm{In}_{2} \mathrm{O}_{3}$ mixture did not at all generate XRD detectable $\mathrm{Ni}_{2}$ In phase (Fig. 3 A2 e', f'), which can, however, be only observed above $450{ }^{\circ} \mathrm{C}$, at higher reduction degree of $\mathrm{Ni}^{2+}$ cations to metal in zeolites A (Fig. 2B d, e). Studies of the selective catalytic reduction of carboxylic acids to alcohols suggest that the presence $\mathrm{Ni}_{2} \mathrm{In}$ phase is responsible for the favorable catalytic effects [17]. Although, nickel and indium cations can be fully reduced up to $550{ }^{\circ} \mathrm{C}$ investigated the $\mathrm{In}_{2} \mathrm{O}_{3} / \mathrm{NiX}$ mixture (Fig. 3A2) however, $\mathrm{Ni}_{2}$ In diffraction lines cannot be observed. The $\operatorname{In}^{0}$ phase, not consumed in the reaction with $\mathrm{Ni}$, would be detectable by XRD only below $156.6^{\circ} \mathrm{C}$, the melting temperature of indium metal. It is to be mentioned that no bulk indium phase could be detected in any of the above-described reduced $\mathrm{In}_{2} \mathrm{O}_{3} / \mathrm{Ni}$-zeolite composites even below the melting temperature of $\operatorname{In}^{0}$. That can 
indicate that the melt indium was hosted and perfectly dispersed in the pores and on the surface of the support and the nickel metal particles and the high dispersion was retained even at room temperature, where the indium phase must be solid.

The formation of the bulk $\mathrm{Ni}_{2} \mathrm{In}$ intermetallic phase significantly depends on the properties of precursor zeolite structures, which symptom is clearly demonstrated in Fig 4. Deeply damaged zeolite structure (NiX < $\mathrm{NiA}<\mathrm{NiP}$ ) means less extent of microporosity consequently less indium atoms are dispersed inside the zeolite framework and result in more alloying indium atoms in the Ni particles. However, these important differences hardly influence the catalytic behavior proven that the quality of the metal surface is the decisive factor (see later).

The average nickel particle sizes, calculated by the Scherrer equation were found to be 30,20 and $11 \mathrm{~nm}$ for the $10 \mathrm{NiX}, 13 \mathrm{NiA}$ and $8 \mathrm{NiP}$ catalysts, respectively. It is not surprising that the same Ni particle sizes were obtained for the In-modified 10NiX sample available small amount of indium outside the crystals. These metal particle sizes signify that such big metal particles can be located only outside of the zeolite crystals and correlate with diffusivity of nickel atoms inside the zeolite crystallites. Consequently, bigger particles can be formed on the large pore faujasite structures (zeolite $\mathrm{X}$ and $\mathrm{Y}$ ). Near the higher diffusion resistance inside the narrow pore zeolite samples the more severe damage of the structure resulting in shorter diffusion paths favor for formation of smaller metal particles.

As a conventional method, the adsorption capacity of the micropores is used to draw conclusion about the zeolite content of zeolite-containing materials. The adsorption isotherms of Fig. 5 show that the adsorbate $\mathrm{N}_{2}$ molecules, having minimum cross sectional diameter of $0.364 \mathrm{~nm}$, adsorbs only on the outer surface of the zeolite NaP crystallites. For this reason, no conclusion can be drawn about the degree of zeolite crystallinity from the low temperature $\mathrm{N}_{2}$ adsorption capacity of such a narrow pore zeolites like zeolite P. Reduction of the $\mathrm{Ni}^{2+}$ lattice cations destabilizes the alumina-rich zeolite structure, which can collapse in the vicinity of the reduced nickel. This destruction of zeolite NiP can generate new meso and macropores. These wider pores are already accessible for nitrogen and have significantly higher adsorption uptake than obtained on $\mathrm{NaP}$. The isotherm of reduced $8 \mathrm{NiP}$ is of type IV instead of a type I isotherm which could be characteristic for zeolites as clearly microporous adsorbents without any detectable mesoporosity. The structure of zeolite NiA undergoes similar change upon reduction as zeolite $\mathrm{NiP}$ although in less extent. Contrary, as a result the $\mathrm{N}_{2}$ uptake decreases upon partial destruction (a point of reference can be the well-known isotherm of 5A zeolite /CaNaA/ or NaX with similar adsorption capacity). The destruction of such narrow pore zeolites annihilates micropores, 
having high adsorption capacity at low pressure, and generates meso and macropores that have lower adsorption uptake at the same low pressure. Zeolite $\mathrm{X}$ has similar framework composition as zeolites A but its micropores are accessible for $\mathrm{N}_{2}$. The $\mathrm{N}_{2}$ adsorption capacity of the zeolite $\mathrm{NiX}, \mathrm{H}_{2}$ treated at $450{ }^{\circ} \mathrm{C}$ is commensurable to that of the $\mathrm{NaX}\left(223 \mathrm{~cm}^{3}(\mathrm{STP}) / \mathrm{g}\right)$. Obviously, the NiX could preserve its structural integrity, because only a relatively small fraction of the nickel cations became reduced under the applied reduction conditions. This can partly apply also for zeolites NiP and NiA.

The facts that $\mathrm{Ni}^{2+}$ zeolite was only partially reduced and the zeolite structure was mostly retained, while nickel particles were formed, which are much larger than the zeolite micropores, suggest that metal particles out of the crystallites are responsible for the catalytic effect of the metal. Indium atoms fixed on the surface or in the upper layer of the supported nickel particles could provide bimetallic sites, having similar catalytic properties as the homogeneous $\mathrm{Ni}_{2} \mathrm{In}$ phase, which was assigned as responsible for the improvement of catalytic properties in former studies [17].

The product distribution obtained using the bimetallic In13NiA catalysts contrast strikingly with that produced on monometallic 13NiA catalyst (Fig. 6) plotted against the time-on-stream (a, b) or the reaction temperature (A, B). 13NiA shows slow activity decay (Fig. 6a) and the hydrodecarbonylation reaction route producing methane is significant. The high hydrogenation activity of this monometallic catalyst results in full methanization of $\mathrm{CO}$ produced primarily in hydrodecarbonylation together with methane. $\mathrm{CO}$ can be detected only in traces. Using, however, In13NiA catalyst, acetic acid can be fully hydroconverted to its reduced derivatives acetaldehyde, ethanol and ethyl-acetate and the hydrogenolysis of $\mathrm{C}-\mathrm{C}$ bond is perfectly eliminated. The In13NiA catalyst, having a balanced activity to hydrogenate $\mathrm{C}-\mathrm{O}$ and $\mathrm{C}=\mathrm{C}$ bonds is a contact for selective ethanol formation from acetic acid (Eq. 1).

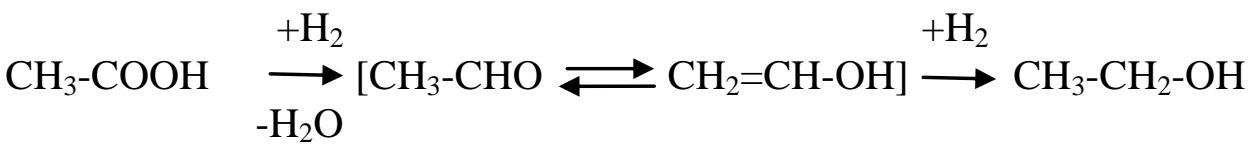

Stable activity and selectivity levels are maintained for at least $40 \mathrm{~h}$ time-on-stream (not shown entirely in Fig. 6b). Increasing the reaction temperature very high ethanol selectivity can be attained and the rates of acetaldehyde reduction and ethyl-acetate hydrogenolysis are increased (Fig. 6B). This example typifies all the Ni-zeolites studied.

Fig. 7 shows the AA conversion and the yields of main products obtained over a commercial, conventionally used Adkins catalyst as a function of reaction temperature compared with the results obtained over all indium doped Ni-zeolites studied in this work. Alcohol from the carboxylic acid was produced with high selectivity over 
all the catalysts, but the new chromium-free catalysts showed the same activity at significantly lower temperatures and narrower temperature range than the Adkins catalyst (Fig. 7A). Thus, $80 \%$ overall conversion of AA was attained already around $300{ }^{\circ} \mathrm{C}$ while on copper chromite only at $350{ }^{\circ} \mathrm{C}$. These zeolite supported bimetallic catalysts were not active in bimolecular and monomolecular dehydration of ethyl alcohol generating diethyl ether and ethylene or ethane, respectively. Main product ethanol and reactant acid can form ethyl acetate as secondary product by esterification, proceeding both in catalytic and non-catalytic route. At higher reaction temperatures, the ester yield decreases indicating that the activation energy of ester hydrogenolysis is higher than that of ester formation (Fig. 7D). Acetaldehyde is a characteristic intermediate reflecting the consecutive nature of the dominant reaction route (Fig. 7B). The acetaldehyde concentration in the product mixture can be reduced by increasing the reaction temperature (for example see Fig. 7C) or the space time.

In Fig. 7A, the conversion curves for the InNi/zeolite catalysts nearly overlap with exception of $6 \mathrm{NiY}$, which contains less nickel resulting in lower activity. Beside lower overall activity, lower efficiency of $6 \mathrm{NiY}$ catalyst is reflected by the highest ethyl acetate yield and lowest ethanol yield being the weakest in ester hydrogenolysis to ethanol. The metal nanoparticle size cannot be correlated with the overall activity. However, the variations of the main product yields obtained for different catalysts prepared from different Ni-zeolite precursors reflect significant differences. The idea that less damaged zeolite structure could be advantageous in respect of the activity of supported metal hydroconversion catalyst proved to be false. The surface of the NiIn nanoparticles must be chemically very similar resulting in very similar selectivities, whereas the size of this surface correlates with catalytic activity. The structure of the support can affect the size of metal nanoparticles. The greater size $(30 \mathrm{~nm})$ of bimetallic particles can be the reason why "NiIn/Ni,H-X", i.e. In10NiX catalyst produce more acetaldehyde and ethyl acetate at higher reaction temperatures than In13NiA or In8NiP. Although these yields are on the decline with increasing temperature similarly to narrow pore zeolite samples, but only at significantly higher reaction temperature because the working metal surface is smaller on bigger particles.

The reaction rate, i.e. the conversions increases with hydrogen partial pressure (Fig. 8A) but decrease with partial pressure of AA (Fig. 8B) in the range of experiments. It seems likely that, strongly adsorbing AA occupies nearly all the active sites at moderate partial pressures suppressing hydrogen, the other reactant. The conversion increased, however, when the hydrogen coverage was increased by increasing the $\mathrm{H}_{2}$ partial pressure, indicating that $\mathrm{H}_{2}$ coverage never exceeded or ever reached that of AA. At the available highest $\mathrm{H}_{2}$ partial pressure the reaction rate could be increased to a maximum by decreasing the AA partial pressure down to a 
value where further decrease of coverage became the rate determining factor (Fig. 8B). The found activity dependence on the reactant partial pressures is in line with the Langmuir-Hinshelwood type kinetics and mechanism.

\section{Conclusions}

Indium-modified aluminosilicate supported $\mathrm{Ni}$ catalysts has been found to be highly efficient for selective reduction of acetic acid to ethanol. Hydrogen reduction of Ni-zeolites at $450{ }^{\circ} \mathrm{C}$ generates nickel particles on the outer surface of the partly amorphised zeolite crystallites. The indium modification can be simply carried out in situ by solid state reduction of admixed indium(III)oxide. Indium doping of $\mathrm{Ni}$ particles effectively promotes reduction of carboxylic acids to alcohols in consecutive steps and hinders mono- or bimolecular alcohol dehydration. Contrary to more reducible and consequently less stable $\mathrm{Cu}$ zeolites, the Ni-zeolites become partially reduced and suffer only partial loss of crystallinity in different extent depending on the type of structure. However, the idea that less damaged zeolite structure could be more advantageous in respect of the activity of the supported metal hydroconversion catalyst proved to be false.

Acknowledgement The authors wish to express their appreciation to Mrs. Ágnes Farkas Wellisch for her technical assistance. Thanks is due to the Hungary-Slovakia Cross-border Co-operation Programme (Project registration number: HUSK/1101/1.2.1/0318) for supporting this research. Thanks to the European Union and the State of Hungary co-financed by the European Social Fund in the framework of TÁMOP 4.2.4. A/2-11-12012-0001 'National Excellence Program’ for the further support.

\section{References}

1 G.W. Huber, S. Iborra, A. Corma, Chem. Rev. 106, 4044 (2006)

2 J.N. Cheda, G.W. Huber, J.A. Dumesic, Angew. Chem. Int. Ed. 46, 7164 (2007)

3 D. Kubicka, Collect. Czech. Chem. Commun. 73, 1015 (2008)

4 M. Stöcker, Angew. Chem. Int. Ed. 47, 9200 (2008)

5 M. F. Demirbas, Appl. Energy 86, S151 (2009)

6 S.N. Naik, V.V. Goud, P.K.Rout, A.K. Dalai, Renew. Sustain. Energy Rew. 14, 578 (2010)

7 J. C. Serrano-Ruiz, R. Luque, A. Sepúlveda-Escribano, Chem. Soc. Rev. 40, 5266 (2011)

8 H.N. Chang, N.J. Kim, J. Kang, C. M. Jeong, Biotechn. Bioproc. Eng. 15, 1 (2010) 
9 M.T. Holtzapple, C.B. Granda, Appl. Biochem. Biotech. 156, 525 (2009)

10 V. Pham, M.T. Holtzapple, M.El-Halwagi, J. Ind. Microbiol. Biotech. 37, 1157 (2010)

11 G. Centi, P. Lanzafame, S. Perathoner, in Catalysis for Alternative Energy Generation (L. Guczi, A. Erdőhelyi, Eds.) Springer, New York, 2012, pp 1-28.

12 D.M. Alonso, S.G. Wettstein, J. Dumesic, Chem. Soc. Rev. 41 (2012) 8075.

13 Gy. Onyestyák, Sz. Harnos, D. Kalló, in: Indium: Properties, Technological Applications and Health Issues, ed. H.G. Woo, H.T. Choi (Nova Science Publishers, New York, 2013) p. 53

14 Sz. Harnos, Gy. Onyestyák, D. Kalló, Micropor. Mesopor. Mater. 167, 109 (2013)

15 Sz. Harnos, Gy. Onyestyák, R. Barthos, M. Stolcova, A. Kaszonyi, J. Valyon, Centr. Eur. J. Chem. 10, 1954 (2012)

16 Sz. Harnos, Gy. Onyestyák, Sz. Klébert, M. Stolcova, A. Kaszonyi, J. Valyon, Reac. Kinet. Mech. Cat. 110, 53 (2013)

17 Gy. Onyestyák, Sz. Harnos, D. Kalló, Catal. Comm. 16, 184 (2011)

\section{Figure captions}

Figure $1 . \mathrm{H}_{2}$-TPR fingerprints demonstrating the reduction of $\mathrm{Cu}$ - and $\mathrm{Ni}$-zeolite catalyst precursors.

Figure 2. HT-XRD patterns of the indium free $13 \mathrm{NiA}$ (A) and $13 \mathrm{NiA} / 10 \mathrm{wt} \% \mathrm{In}_{2} \mathrm{O}_{3}$ mixture (B) catalyst precursors, treated in $\mathrm{H}_{2}$ flow for 30 min at different temperatures.

Figure 3. HT-XRD patterns of the $15 \mathrm{CuX}(\mathrm{A} 1), 10 \mathrm{NiX}(\mathrm{A} 2), 17 \mathrm{CuP}(\mathrm{B} 1)$ and $8 \mathrm{NiP}(\mathrm{B} 2)$ zeolites treated in $\mathrm{H}_{2}$ flow for $30 \mathrm{~min}$ at different temperatures with and without $10 \mathrm{wt} \% \mathrm{In}_{2} \mathrm{O}_{3}$ admission.

Figure 4. Comparison of HT-XRD patterns after indium doping of 10NiX, 13NiA and 8NiP zeolites.

Figure 5. Nitrogen adsorption isotherms obtained at $-196{ }^{\circ} \mathrm{C}$ for comparison of $\mathrm{NaP}, \mathrm{NiP}, \mathrm{NiA}$ and $\mathrm{NiX}$ samples after reducing treatment in $\mathrm{H}_{2}$ flow at $450^{\circ} \mathrm{C}$. 
Figure 6. Stacked area graphs of product distributions obtained in the hydroconversion of AA over catalysts $13 \mathrm{NiA}$ without $(\mathrm{a}, \mathrm{A})$ and with $(\mathrm{b}, \mathrm{B})$ indium doping, as a function of time-on-stream at $300{ }^{\circ} \mathrm{C}$ and reaction temperature. The total pressure was 21 bar and the WHSV of AA was $1 \mathrm{~h}^{-1}$.

Figure 7. Conversion curves (A) and yields of main products (B: ethanol, C: acetaldehyde, D: ethyl acetate) obtained from the hydroconversion of AA over commercial Adkins and indium doped zeolite based catalysts: In6NiY, In10NiX, In13NiA and In8NiP, as a function of reaction temperature. The total pressure was 21 bar and the WHSV of AA was $1 \mathrm{~h}^{-1}$.

Figure 8. Stacked area graphs of AA hydroconversion as a function of hydrogen (A) and acetic acid (B) partial pressures at $320^{\circ} \mathrm{C}$ over In $13 \mathrm{NiA}$ catalyst. 
Fig.1.

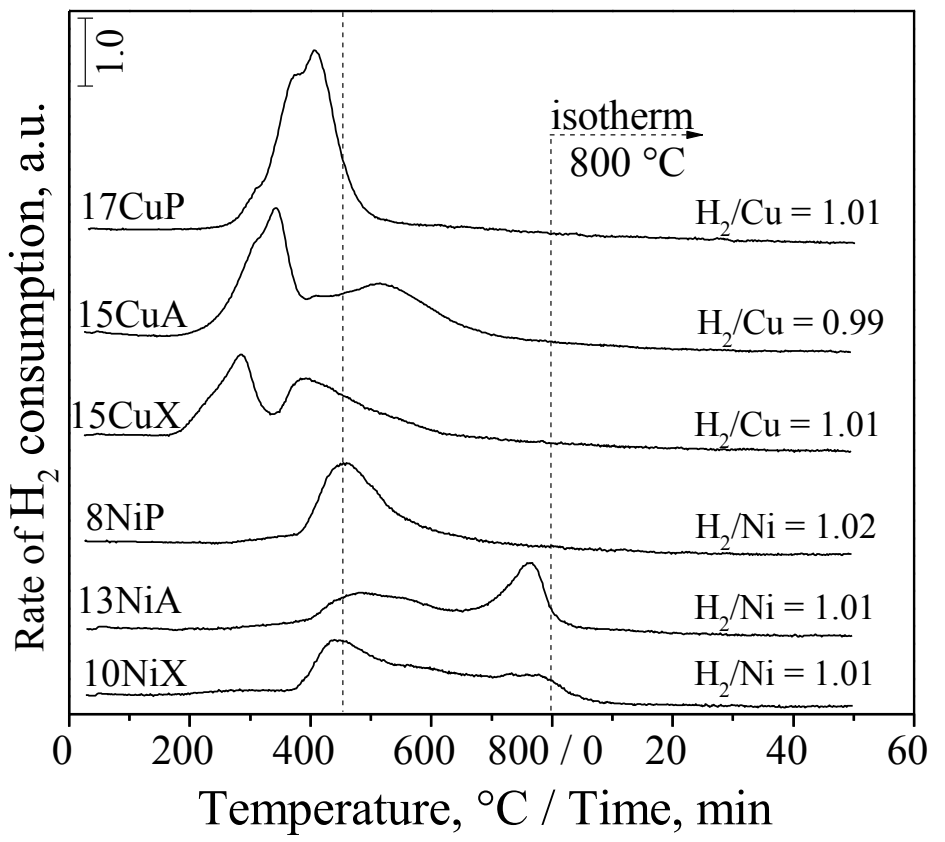

Fig.2.

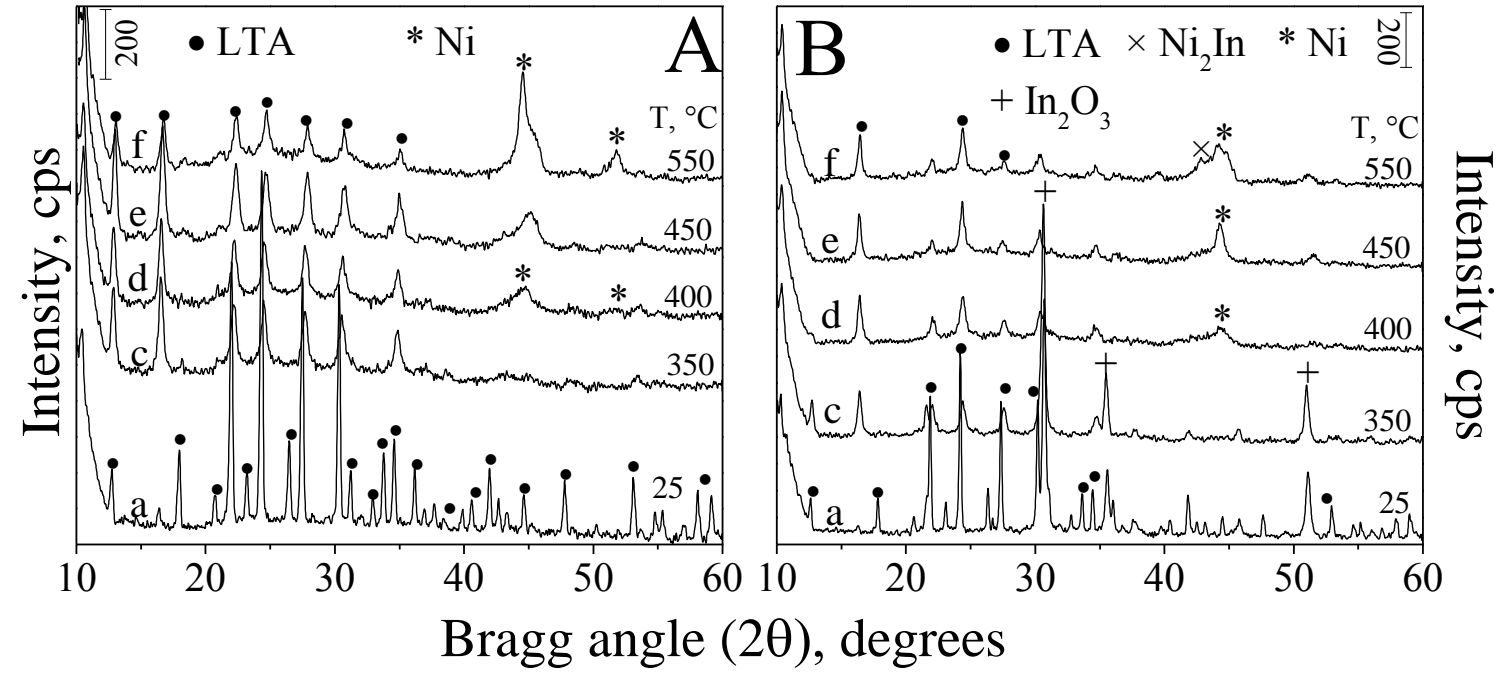


Fig.3.

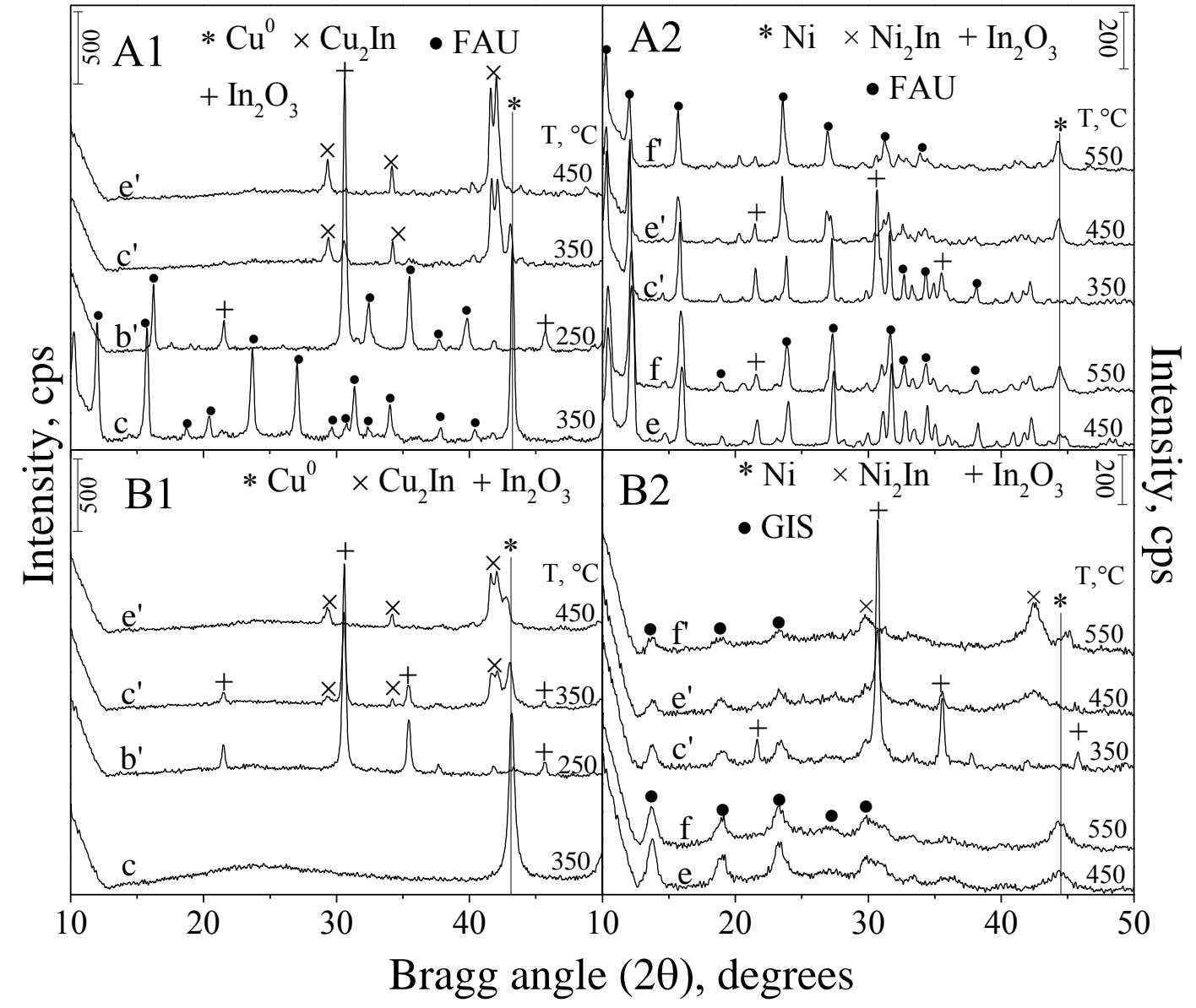

Fig.4.

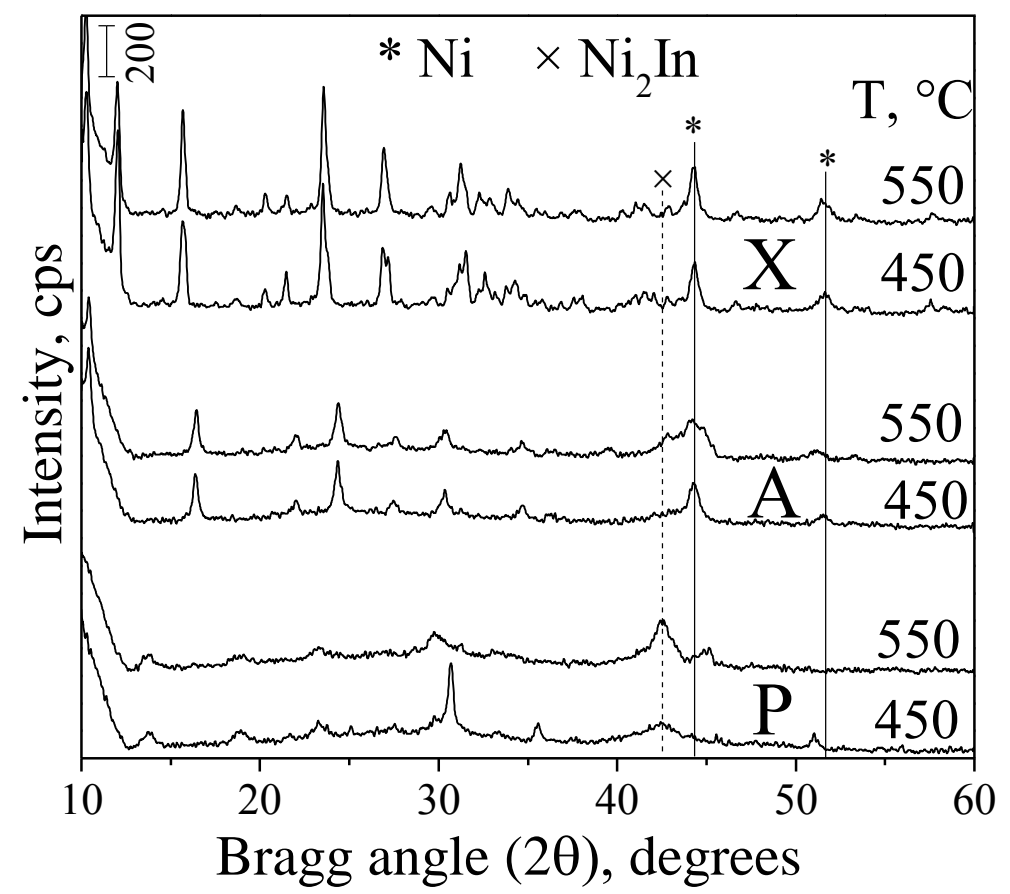


Fig.5.

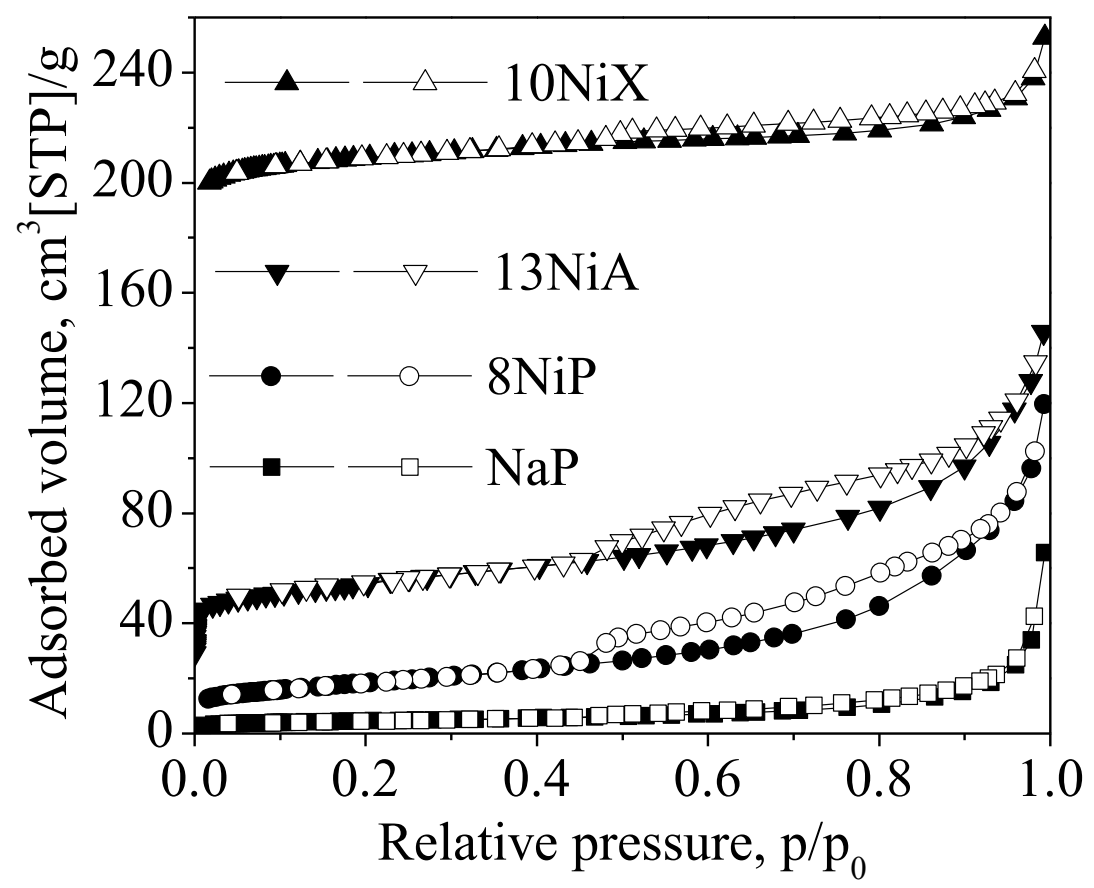

Fig.6.
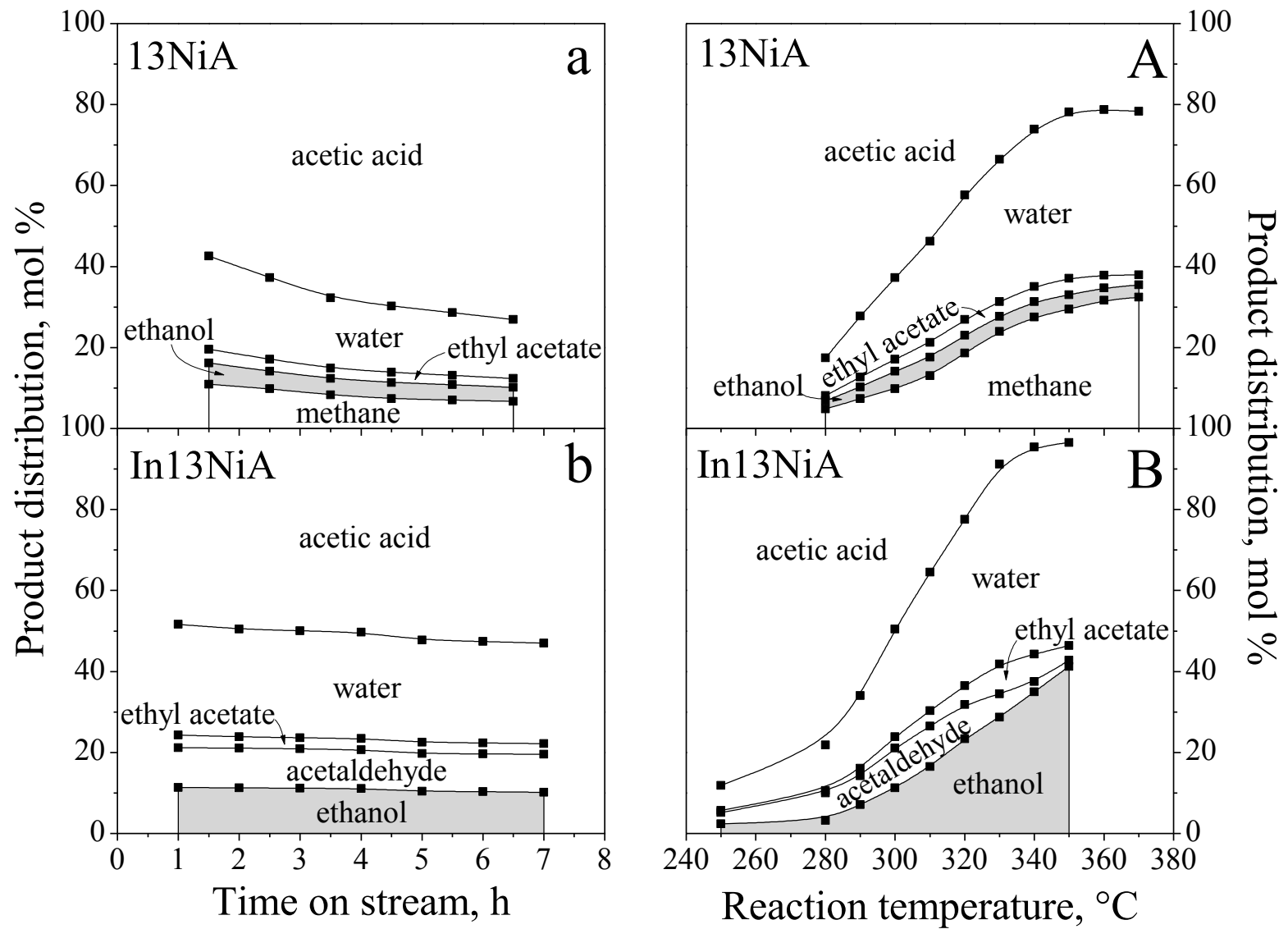
Fig.7.
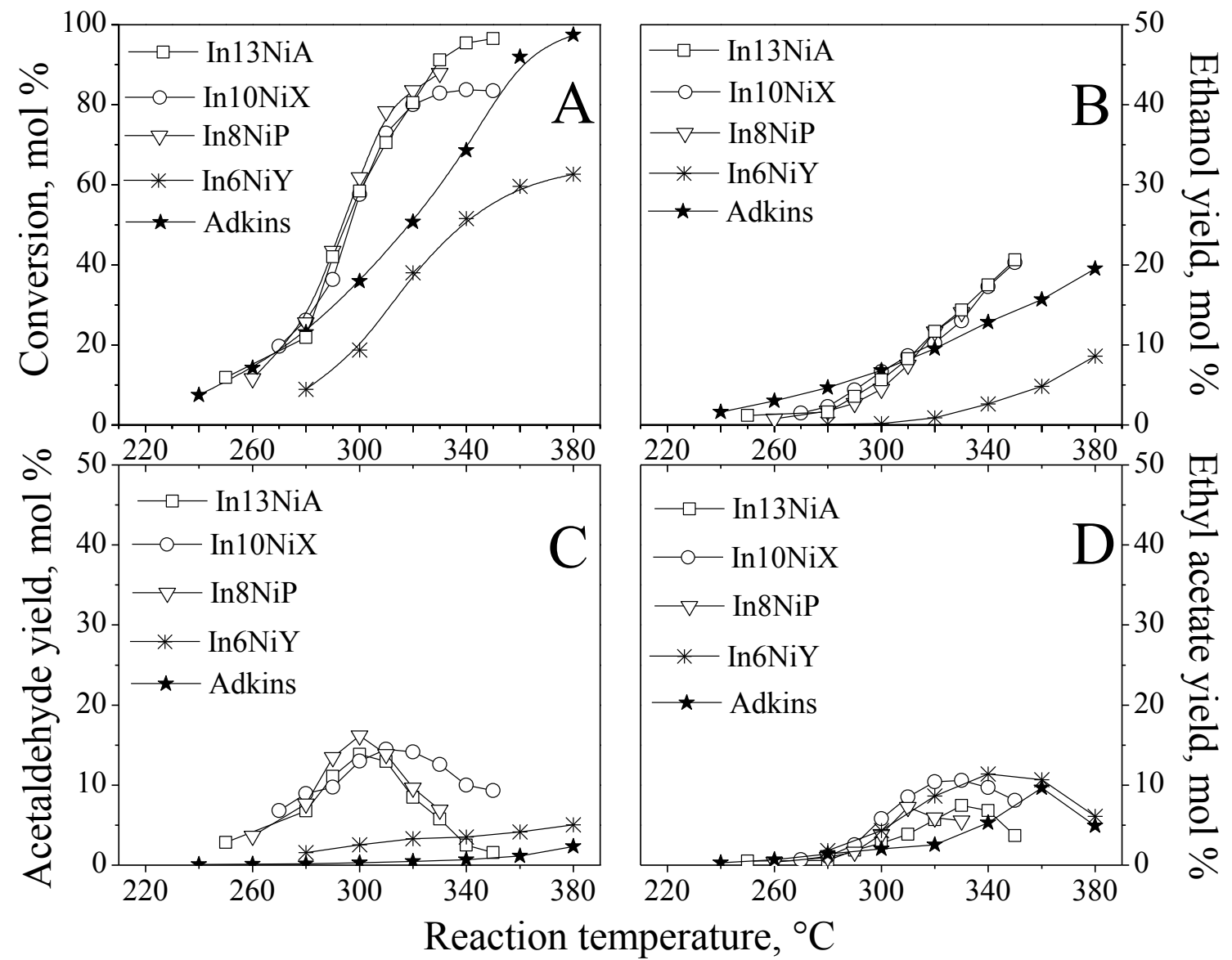

Fig. 8.
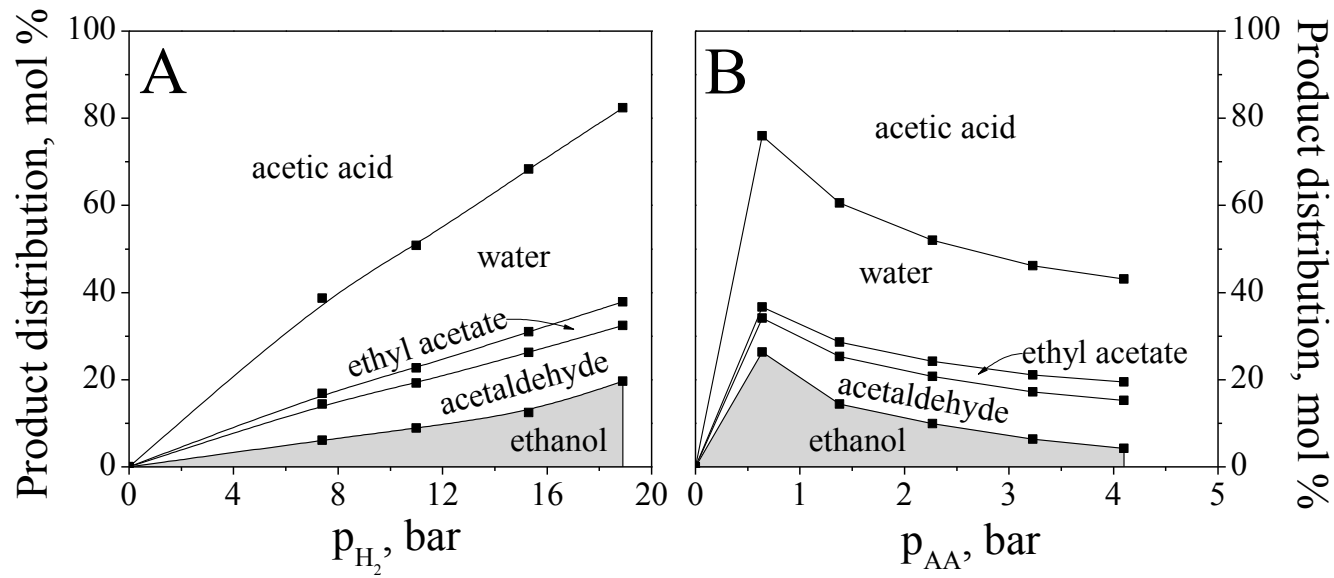